$$
\because \therefore
$$

$$
\begin{aligned}
& 1 N \cdot 39 \\
& 126271
\end{aligned}
$$

NASA Technical Memorandum 107671

\title{
DYNAMIC TEST/ANALYSIS CORRELATION USING REDUCED ANALYTICAL MODELS
}

Paul E. McGowan, A. Filippo Angelucci, and Mehzad Javeed

September 1992

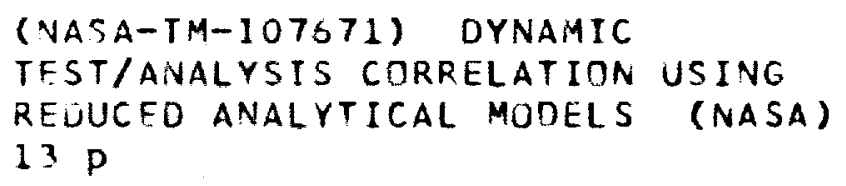

\section{N/5}

National Aeronautics and Space Administration

Langley Research Center Hampton, Virginia 23681 


\title{
DYNAMIC TEST/ANALYSIS CORRELATION USING REDUCED ANALYTICAL MODELS
}

\author{
Paul E. McGowan * A. Filippo Angelucci ${ }^{+}$ \\ NASA Langley Research Center \\ Hampton,VA 23665-5225
}

\author{
Mehzad Javeed * \\ and Lockheed Engineering and Sciences Company \\ Hampton, VA 23665-5225
}

\begin{abstract}
Testlanalysis correlation is an important aspect of the verification of analysis models which are used to predict on-orbit response characteristics of large space structures. This paper presenis results of a study using reduced analysis models for performing dynamic lestlanalysis correlation. The reduced test-analysis model (TAM) has the same number and orientation of degrees-of-freedom (DOF) as the test measurements. Two reduction methods, static (Guyan) reduction and the Improved Reduced System (IRS) reduction, are applied to the lest/analysis correlation of a laboratory truss structure. Simulated lest results and modal test data are used 10 examine the performance of each method. It is shown that selection of DOF to be retained in the TAM is critical when large siructural masses are involved. In addition, the use of modal test results may provide difficulties in TAM accuracy even if a large number of DOF are retained in the TAM.
\end{abstract}

\section{Introduction}

Verification of analytical models using ground vibration test results is common practice in many aerospace applications. In many cases a finite element model (FEM) is used to analyze the structure and determine its response due to various excitations and under various boundary conditions. Verification of the FEM is thus required in order to use with confidence the model to produce response or load predictions. The verification process is centered on ground test results, and a subsequent correlation of the analysis predictions of these quantities is then conducted to verify the FEM accuracy. This correlation is traditionally limited to comparison of modal parameters, primarily frequencies and mode shapes since terms from the FEM mass and stiffness matrices cannot be explicitly verified on the basis of laboratory tests. However, the FEM and test results typically cannot be directly compared since the FEM often contains many more degrees-of-freedom (DOF) than the responses recorded in the test configuration.

One approach for allowing the tes/analysis correlation is to reduce the FEM to the same DOF as those measured in a test. A number of studies involving test/analysis correlation of spacecraft have been previously reported in the literature [1-6]. This paper uses analytically derived "lest" results to demonstrate the reduction methodology, and includes an application to a large-order problem from the class of flexible space structures proposed for future missions. Two reduction methods are selected for detailed study. Results are presented to demonstrate each method's accuracy through application to a laboratory truss structure using experimental test data.

\footnotetext{
- Aerospace Research Engineer, Member AIAA, ASME

+ Aerospace Resenrch Engineer, Member AIAA

* Senior Engineer
}

A test-analysis model (TAM) is an analytical model reduced to the same DOF as the instrumented DOF in a modal test. The TAM provides a direct link which allows the modal parameters of the FEM to be correlated to the test. This link is depicted in the schematic of Fig. 1. The full structure FEM model consists of a relatively large number of DOF, $n$. In contrast, the test model typically has fewer DOF, r, equal in size to the number of instrumented test DOF. For the test model the number of test modes, $m$, is often smaller than $r$. A model reduction procedure yields the TAM from the analysis results, of dimension $\mathrm{r} \times \mathrm{m}$, which can be directly correlated with the test results.

A variety of model reduction methods with varying levels of complexity have been developed over the past quarter century [7-12]. These methods can be categorized by the information used in the reduction procedure as either static, dynamic, or exact reductions. A common feature of each is the development of a transformation matrix, referred to hercin as " $D$ ". This matrix relates the DOF retained in the analysis set to those DOF omitted, and is used to form the reduced mass and stiffness matrices (Fig. 2.). Each reduction method yiclds a different transformation matrix. However, the solution procedure for the reduced system is identical for each method once the transformation matrix has been developed.

In previous works [13,14], the transformation matrices produced from several different reduction methods have been compared. In general, static methods involve frequencyindependent transformations. In contrast, the dynamic and exact reduction methods consist of frequency-dependent transformation matrices, which use modal properies of the full system to compute the reduced system matrices. Inasmuch as the the static methods are not dependent on knowledge of the full system modal properties, they produce reduced models for more general application. In this study. two static methods, Guyan reduction and the Improved 
Reduced System (IRS) reduction, were selected for detailed evaluation and application to example problems.

Guyan reduction [7] has been a frequently used method in structural analysis. The IRS reduction method [10] was developed as an improvement to Guyan reduction. Reduced models derived from both methods reproduce information from the full system stiffness matrix, therefore they are exact for static equilibrium situations. The methods differ, however, in their treatment of inertial effects of the omitted degrees-of-freedom (DOF). Guyan reduction does not account for inertial forces at the omitted DOF. However, the IRS method uses the Guyan-reduced solution as a first approximation and then develops an inertial force correction factor. Therefore, when mass associated with the omitted DOF is significant, the IRS method is expected to perform better than the Guyan method.

\section{Application Example}

The model reduction and correlation procedures are applied to the testanalysis correlation of a laboratory structure. The focus structure was a ten-bay, cantilevered truss structure constructed of erectable aluminum joints and truss members. This truss is one of a series of structures being used in the Dynamic Scale Model Technology (DSMT) research program at NASA Langley Research Center [15]. Each bay of the generic truss is a cube with the side dimension of 1.64 feet. The generic truss possesses several properties which make it similar to many large, flexible space structures. The presence of a large concentrated mass on a relatively light, distributed mass structure is one such similarity. Two square plates were attached to the free end of the truss. These plates weighed $86.25 \mathrm{lbs}$., and accounted for approximately 60 percent of the total test article weight of 147.4 lbs. Dynamic characteristics of the response exhibited by the truss resemble those for large space truss structures, as well. The truss responds with low, closely-spaced frequencies and light damping.

Using MSCNNASTRAN, each truss member was modeled as a rod element, with an effective axial stiffness to account for the presence of the joint. With $\mathbf{4 4}$ nodal points on the truss and 16 nodal points on the plates, the FEM analysis contains 180 translational DOF. Analysis frequencies of the first nine vibration modes are shown along with the mode shapes in Fig. 3. The global modes consist of three closely spaced bending mode pairs (BI-B3), two torsional modes ( $\mathrm{T} 1$ and $\mathrm{T} 2)$, and one axial mode (AI).

Modal tests of the generic truss were performed to determine vibration frequencies and mode shapes using 98 translational accelerometers and two excitations [16]. As depicted in Fig. 4, the truss dynamic response was measured at each of the 44 truss nodal joints in two directions perpendicular to the truss longitudinal axis. Axial acceleration measurements were also acquired at the two driving points, at the four truss nodes of the free end, and at the four nodes of the truss mid-frame.

\section{Model Reduction Sludies}

Prior to correlating the TAM with the test results, accuracy of the TAM must be established. This is evaluated by reordering and partitioning the FEM modes to the same DOF as the TAM and correlating the TAM with the partitioned FEM modes. In this paper, three criteria are used to evaluate accuracy of the TAM predictions relative to the exact system modes or to the test results: 1) frequency error, 2) Modal Assurance Criterion (MAC), and 3) Cross-orthogonality (XO). The first criterion indicates the ability of a TAM to predict frequencies of the exact system. The two latter criteria indicate the accuracy of the TAM's mode shape predictions.

In many actual situations for large space structures, a large number of response measurements may not be available to ensure adequate representation of the truss spatial properties and mass distribution. Consequently, a comparison of the reduced models' performance is conducted using two models with a reduced number of DOF on the truss section and on the tip plates. Arrows in Figures 5 and 6 indicate the location of a DOF retained in the reduced system model. The first DOF set retains 26 DOF in the reduced model. Set 2 is identical to that used in set 1 except for the removal of the tri-axial DOF on the tip plates. Since the tip plates account for such a large percentage of the total structural mass, this simulates the effects of not fully instrumenting a large mass on a space structure.

Table 1 compares the resulting frequency errors for the two reduction methods. For the first set, the Guyan-reduced model produces significantly larger frequency errors than the IRS method for the truss axial mode and for the higher bending and torsion modes. Additionally, the effect of not retaining the DOF on the tip plates impacted the Guyan method significantly more than the IRS method as evident by the relative frequency errors for set 2 . Prediction of the higher truss modes by the Guyan method resulted in large frequency errors. Also with set 2, the eighth FEM mode was not predicted by the Guyan-reduced model. This result is not unexpected due to the inaccurate treatment of inertial effects of the omitted DOF by the Guyan method. Conversely, the IRS TAM predictions were accurate, with the exception of an 8 percent error for the eighth FEM mode. Interestingly, the IRS-reduced model was able to accurately predict the sixth system mode, an axial mode, even though only 2 axial DOF were retained in the second sensor set.

The resulting MAC and XO mode shape correlations for each reduction method are displayed in Figures 7 and 8 . For set 1 , the XO correlation values from the Guyan method degrade at the higher modes. In particular, correlation parameters for the sixth, eighth and ninth modes indicate a loss in accuracy. These mode shape results correspond to the larger frequency errors in Table 1. Correlation values for the modes with the IRS model show excellent accuracy in predicting the full system mode shapes. 
When all of the DOF were eliminated from the plates in set 2. the mode shape correlations become increasingly difficult to interpret as seen in Figures 9 and 10. Correlation parameters for the higher modes using the Guyan method dropped below a value of 90 . Also, the magnitude of the offdiagonal correlation values become large, indicating the inability of the reduction methods to produce uncorrelated mode shapes without retention of sensors on the tip plates. In almost all cases, the IRS method produced diagonal terms near 100 . However, the first mode of the IRS TAM produced a XO correlation value of approximately 200 with respect to the eighth FEM mode. This corresponds to the large frequency error of over $\mathbf{8}$ percent for this mode in Table 1.

\section{TesvAnalysis Correlation}

Frequency correlations for the reduced system analysis, using both Guyan and IRS reduction, and the test results using 98 DOF are presented in Table 2 . Test frequencies as displayed in the table are generally lower than the analysis frequencies. This trend is not unusual in practical situations since local compliances in the test structure are often not modeled accurately with a limited discretization. The test results indicate that the second torsional mode, T2, had a higher frequency than the first mode of the third bending mode pair (B3). Thus, modes seven and eight switched their order of occurrence with respect to the analysis results. This is most likely caused by an unmodeled rotational stiffness in the test configuration such as the excitation shaker allachment to the truss. Accordingly, the frequency errors displayed in Table 2 for both reduced models correspond closely to those oblained from the full model analysis. Frequency errors are comparable for the two methods and are generally small except for the first truss torsion mode, which has an error over 10 percent. Further refinement of the tip plate mesh density would more accurately account for the plate rotational inertia and improve the frequency correlation for this mode.

Correlation of the reduced model mode shapes and test mode shapes using the MAC criterion is displayed in Fig. 11. The MAC correlations for both methods are identical. All diagonal terms are near 100, which indicales the modes predicled by each method have the same shape and are close to the test modes. Recall that modes seven and eight of the test reversed their order of occurrence as seen in the correlation graphs at the seventh and eighth row positions.

When the reduced mass matrices are introduced via the XO correlation criteria, results are significantly different for the two methods. The Guyan reduced model demonstrated excellent correlation with the test results as depicted in the left-hand graph of Fig. 12. Generally, all the diagonal terms are near 100 and only a small number of off-diagonal terms are present. In contrast, the IRS method produced poor correlation values as shown in the right-hand portion of Fig. 12. Many of the off-diagonal terms exceeded a value of 50 . while the diagonal terms were also very low. Further examination of the IRS method using actual lest data is required to explain the poor correlation.

\section{Assessment of Results}

The previous section demonstrated that the 98 DOF sensor set is more than sufficient to produce an accurate TAM. Additionally, the MAC values using both reduced models produced comparable mode shape correlations with the test mode shapes. Hence, the poor XO correlation described above is attributed to the IRS-reduced mass matrix. This can be explained by examining the correction terms added to the Guyan-reduced mass matrix by the IRS method. The correction term is subject to inordinately large values, in particular when large mass terms are contained in the omitted DOF. For the truss application problem only four node points on the tip plate are retained in the $98 \mathrm{DOF}$ sensor set. Accordingly, the majority of the plate mass is contained in the omitted set of DOF. This causes the IRS correction term to become extremely large and results in a poorly structured reduced mass matrix for this example.

Based on the simulation study results the IRS method would be expected to produce more accurate mode shape correlations than the Guyan method using the modal lest data. The IRS. reduced model produced excellent correlation results when the partitioned FEM mode shapes are used in the correlation. However, the results shown in Fig. 12 indicate that the cross-orthogonality correlation parameter using the IRS. reduced mass matrix is sensitive to inaccuracies in the test mode shapes. Also, errors introduced by extraction of the test modes from the parameter estimation algorithms contributed to the inaccurate correlations presented above. Consequently, use of the IRS method with laboratory test results, which involve structures with large masses that are not fully instrumented, requires the analyst to select carefully the omitted DOF.

\section{Summary}

Each of the reduction methods can provide acceptable accuracy with a sufficient, but often large, choice of DOF retained in the reduced model. The analyst must place increased emphasis on selecting a proper set of reduced DOF and on selecting a reduction method consistent with the DOF of choice, all within appropriate limits for the structure being analyzed. It is important to understand the accuracy and limitations of each method prior to its use in order to select a reduction method consistent with the structure being analyzed and the level of fidelity required.

In general, this study confirmed that use of the IRS reduction method has several advantages over Guyan reduction. Simulated results indicate the IRS method produces comparable or better results than the Guyan method in most applications. The IRS method produced accurate frequency predictions in all cases considered. Also, it provides an 
accurate tool for performing pre-test analysis, wherein, the full system FEM is used in the correlation. These observations are consistent with those presented in the literature.

Difficulties observed with the IRS method using laboratory test data, when large masses are omitted, is a result previously unreported in the literature. This is a subject requiring further research before the IRS method can be used for general applications. Development of criteria which define operating limits for the method is required. Moreover, additional studies need to be conducted using laboratory test data from realistic structures. These results place increased burden on the analyst to select carefully the omitted DOF and to consider the most appropriate method for the application.

\section{References}

1. Kammer, D. C.; Jensen, B. M.: and Mason, D. R.: Test/Analysis Correlation of the Space Shutue Solid Rocket Motor Center Segment, AIAA Joumal of Spacecraft and Rockets, Vol. 26, No. 4, July-Aug 1989, pp 260-273.

2. Brillhart, R. D.; Freed, A. M.; and Hunt, D. L.: Modal Test and Correlation of the Commercial Titan Dual Payload Carrier, Proceedings of the Eighth International Modal Analysis Conference, Kissimmee, Florida, February 1990, pp. 912-918.

3. Flanigan, C. C.: Test/Analysis Correlation Using Design Sensitivity Optimization -- Does It Work?, SAE Paper 881531, Aerospace Technology Conference, October 1988.

4. Freed, A. M.; and Flanigan, C. C.: A Comparison of Test-Analysis Model Reduction Methods, Sound and Vibration, Vol: 25, No. 3, March 1991, pp. 30-35.

5. Avitabile, P., O'Callahan; J. C., Milani, J.: Comparison of System Characteristics Using Various Model Reduction Techniques, Proceedings of the Seventh International Modal Analysis Conference, Las Vegas, Nevada, February 1989. pp. $1109-1115$.

6. Urgueira, A.; Lieven, N. A. J.; and Ewins, D. J.: A Generalised Reduction Method for Modal Testing, Procecdings of the Seventh Intemational Modal Analysis Conference, Las Vegas, Nevada, February, 1989, pp. 22-27.

7. Guyan, R. J.: Reduction of Stiffness and Mass Matrices, AlAA Joumal. Vol. 3, No. 2, February 1965, p. 380.
8. Miller, C. A.: Dynamic Reduction of Structural Model, Joumal of the Structural Division ASCE, Vol. 106, October 1980, pp. $2097-2108$.

9. Paz, M.: Dynamic Condensation, AIAA Journal, Vol. 22, No. 5. May 1984, pp. 724-727.

10. O'Callahan, J. C.: A Procedure for an Improved Reduced System (IRS) Model, Proceedings of the Seventh International Modal Analysis Conference, Las Vegas, Nevada, February 1989, pp. 17-21.

11. O'Callahan, J. C.; Avitabile P. A.; Riemer, R.: System Equivalent Reduction Expansion Process (SEREP), Proceedings of the Seventh International Modal Analysis Conference, Las Vegas. Nevada, February 1989, pp. 29-37.

12. Kammer, D. C.: Test-Analysis Model Development Using an Exact Modal Reduction, International Journal of Analytical and Experimental Modal Analysis, October 1987. pp. 174- 179.

13. McGowan, P. E.: Dynamic Test/Analysis Correlation Using Reduced Analytical Models. Master of Science Thesis, Department of Mechanical Engineering and Mechanics, Old Dominion University, Norfolk, Virginia, June 1991.

14. Angelucci, A. F.; Javeed, M; and McGowan, P. E.: Test-Analysis Model (TAM) Creation and Verification Process. NASA TM 1-17071, Jenuary, 1992.

15. McGowan, P. E.; Javeed, M.; and Edighoffer, H. H.: Status of DSMT Research. NASA TM-102764, January 1991.

16. McGowan, P. E.; Smith, S. W.: and Javeed, M.: Experiments for Locating Damaged Members in Truss Structure, JPL Proceedings of the Workshop on Identification and Control of Flexible Space Structures, March 1990, pp. 571-615.

\section{Acknowledgements}

Messrs. Andy Freed and Josh Gordis of the Structural Dynamics Research Corporation, Engineering Services Division. San Diego, Califomia provided valuable help in analyzing results of the reduction studies. 
Table 1. Effect of Plate Mass DOF Selection on Model Reduction Accuracy.

\begin{tabular}{|c|c|c|c|c|c|} 
Mode & Mode & \multicolumn{4}{|c|}{ Srequency Error (\%) } \\
Number & Shape & Guyan & IRS & Guyan & Set 2 \\
\hline 1 & B1 & 0.006 & 0.005 & 1.411 & 0.005 \\
2 & B1 & 0.010 & 0.003 & 0.761 & 0.008 \\
3 & T1 & 0.207 & 0.000 & 4.601 & 0.004 \\
4 & B2 & 0.911 & 0.001 & 14.542 & 0.106 \\
5 & B2 & 0.956 & 0.000 & 5.665 & 0.001 \\
6 & A1 & 8.209 & 0.001 & 18.811 & 0.077 \\
7 & T2 & 3.544 & 0.011 & 23.383 & 1.097 \\
8 & B3 & 6.074 & 0.116 & & 8.112 \\
9 & B3 & 7.134 & 0.069 & 21.298 & 0.212
\end{tabular}

* Mode not predicted.

Table 2. Reduced Models and Test Frequency Correlation Using 98 DOF.

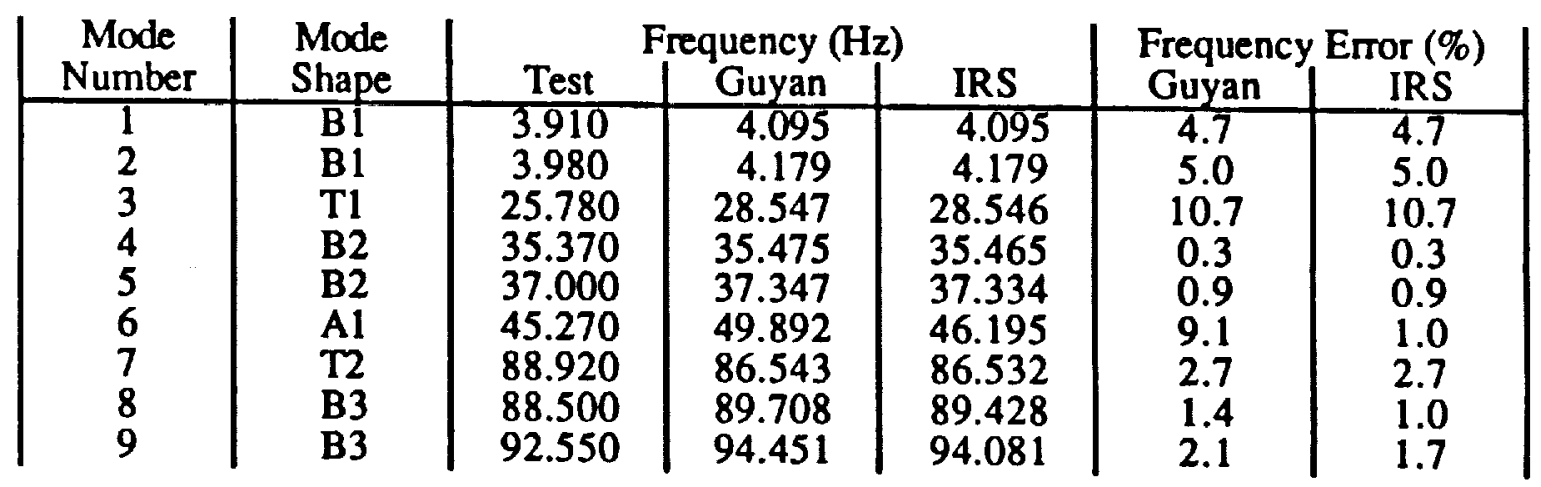




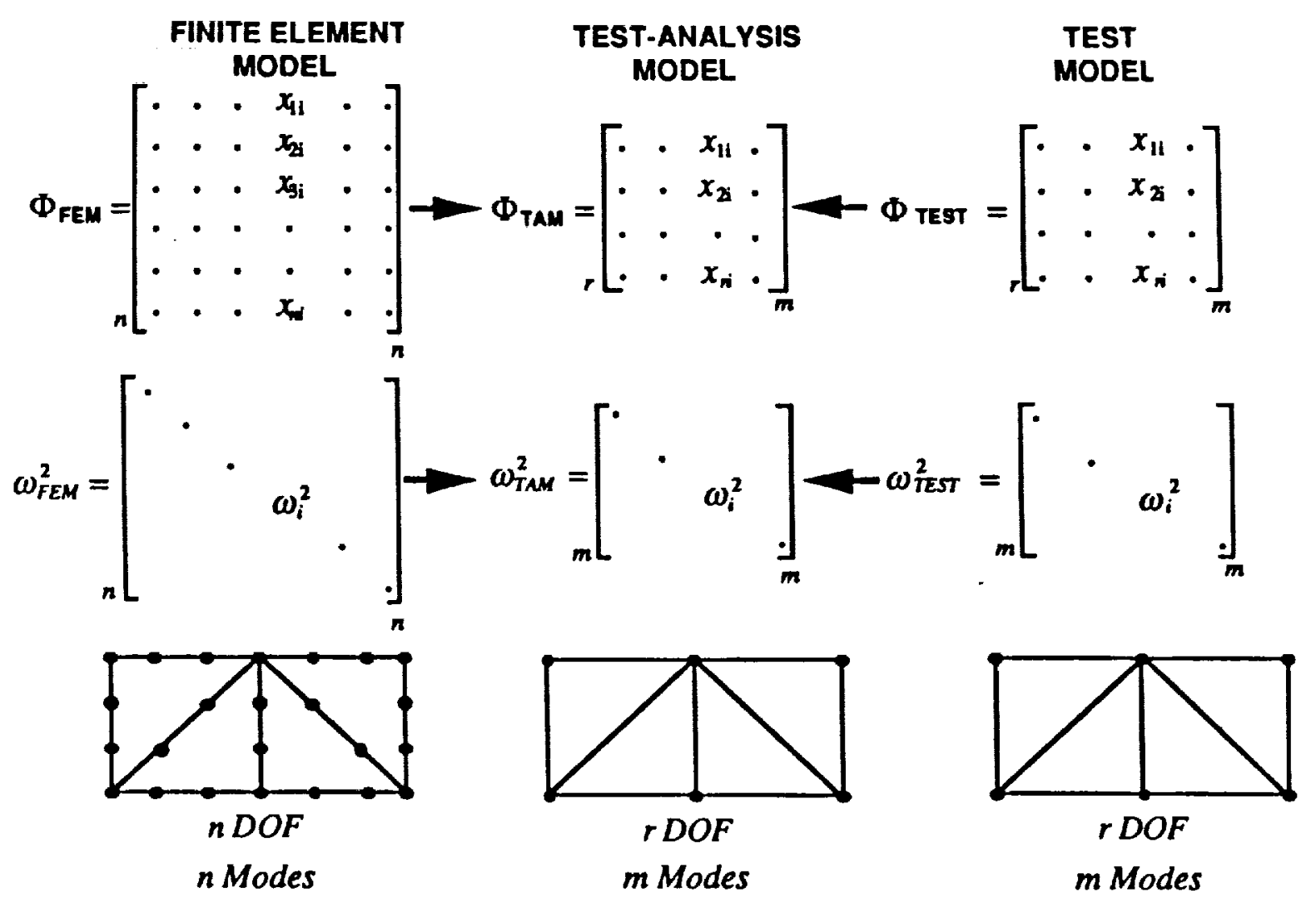

Figure 1. Test-analysis model concept.

$$
\begin{aligned}
& \text { FEM EQUATION OF } \\
& \text { MOTION: }
\end{aligned}
$$

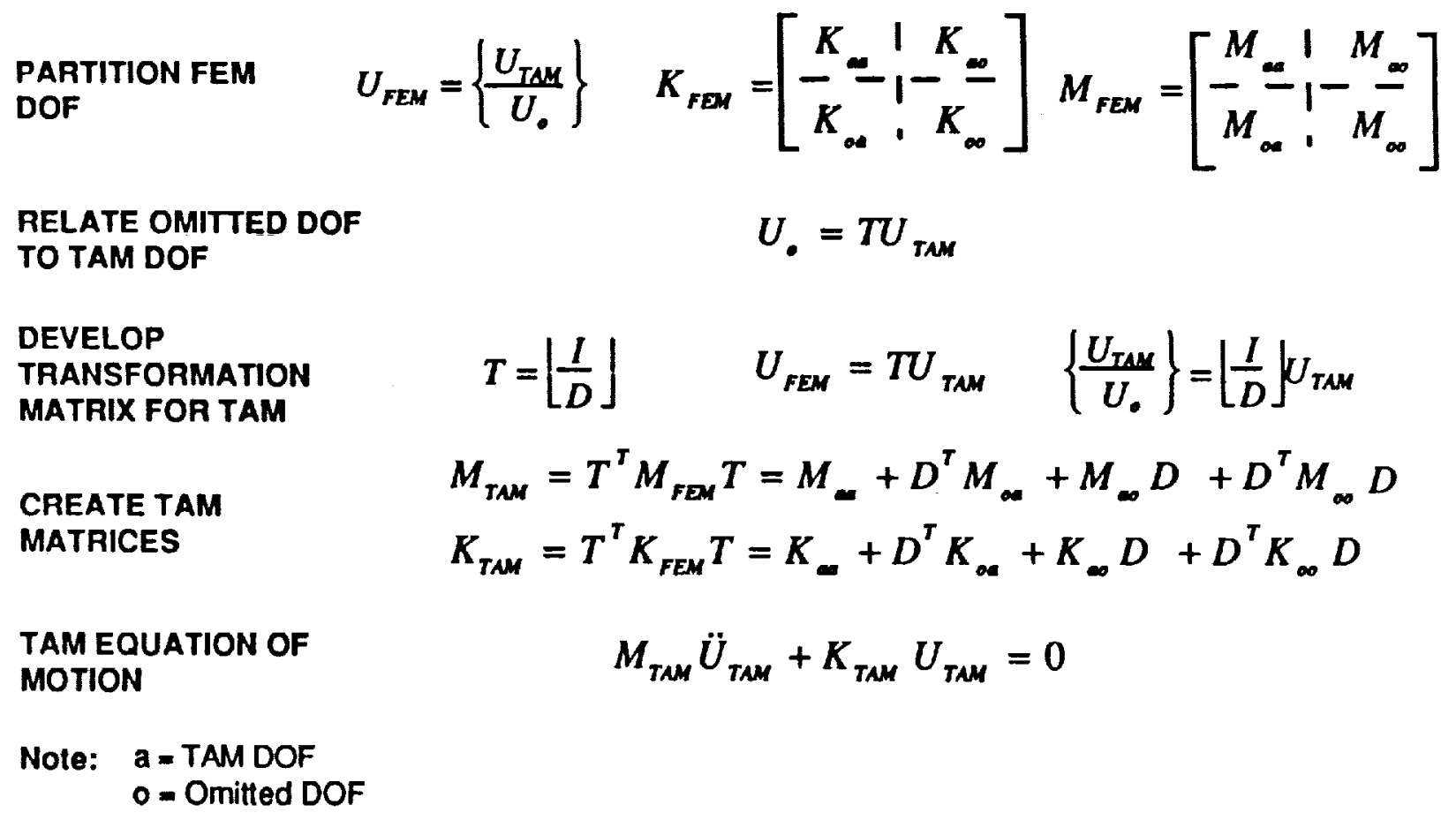

Figure 2. Development of TAM from FEM. 


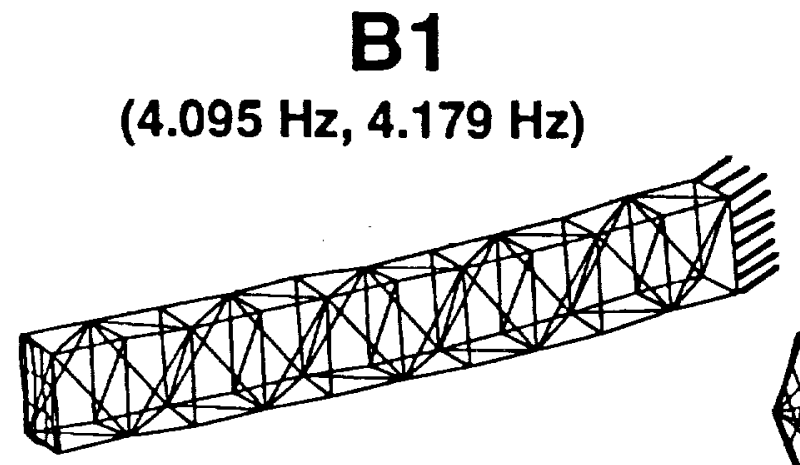

T1

(28.546 Hz)
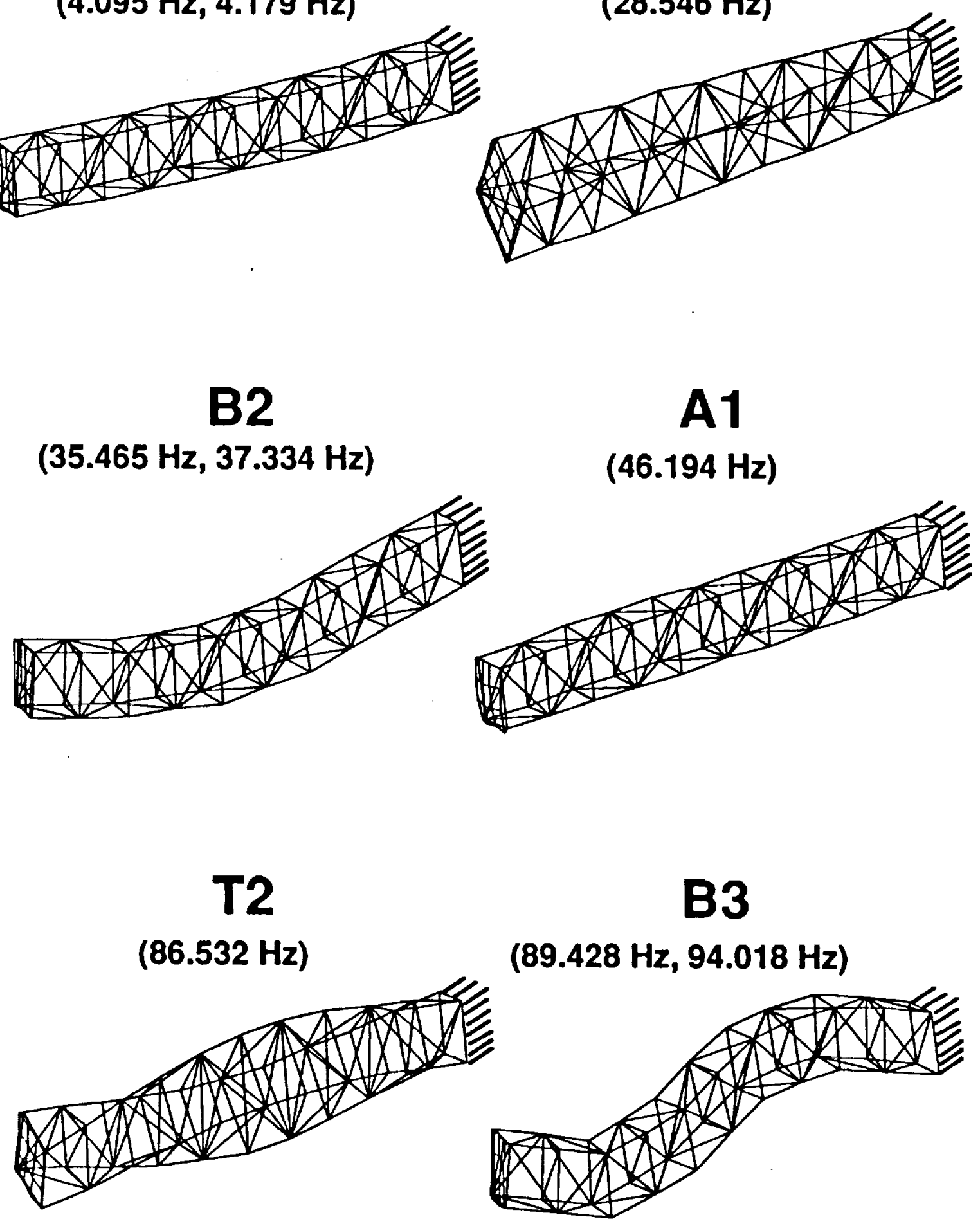

Figure 3. Truss analysis mode shapes and frequencies. 


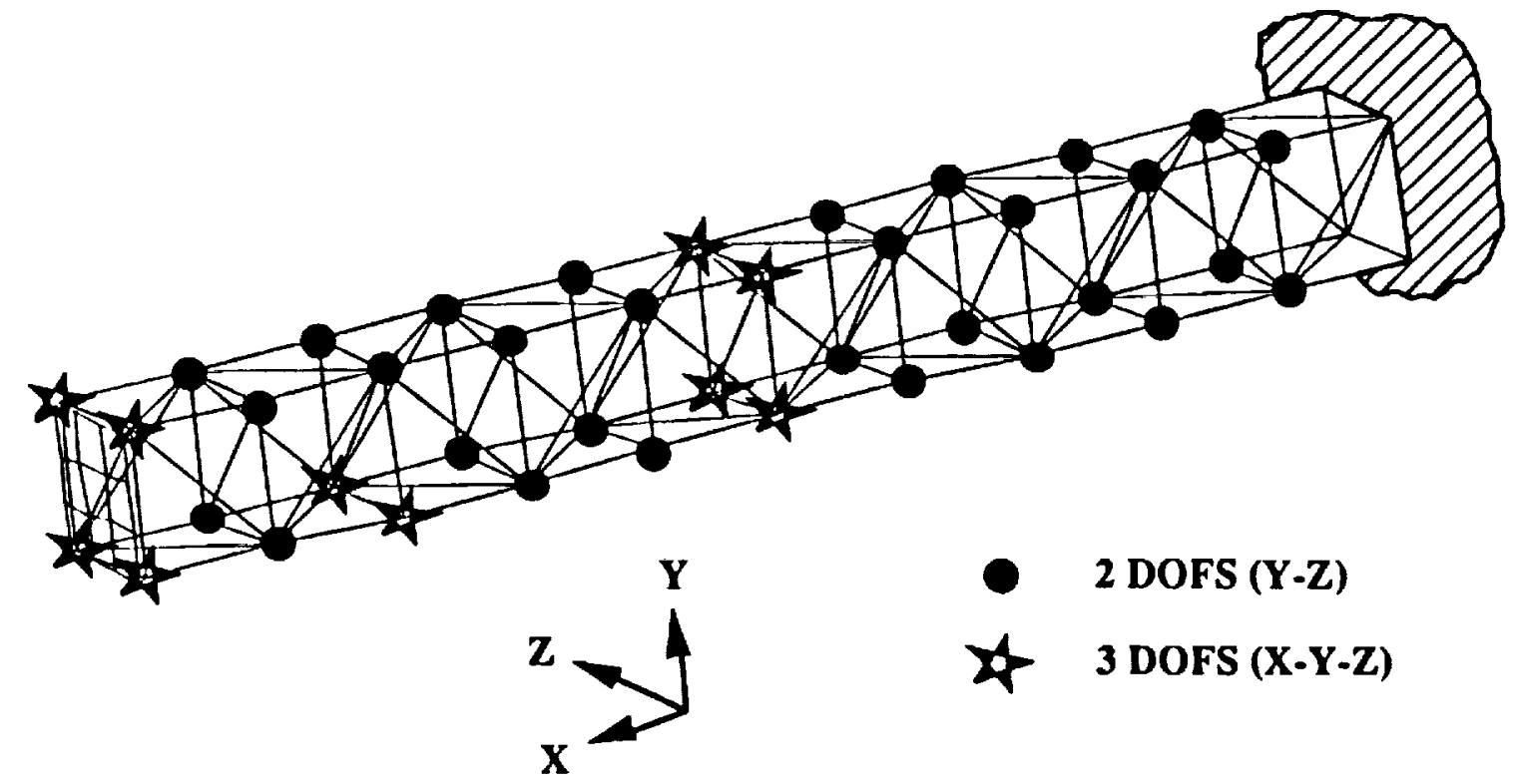

Figure 4. Accelerometer locations for modal test of generic truss.

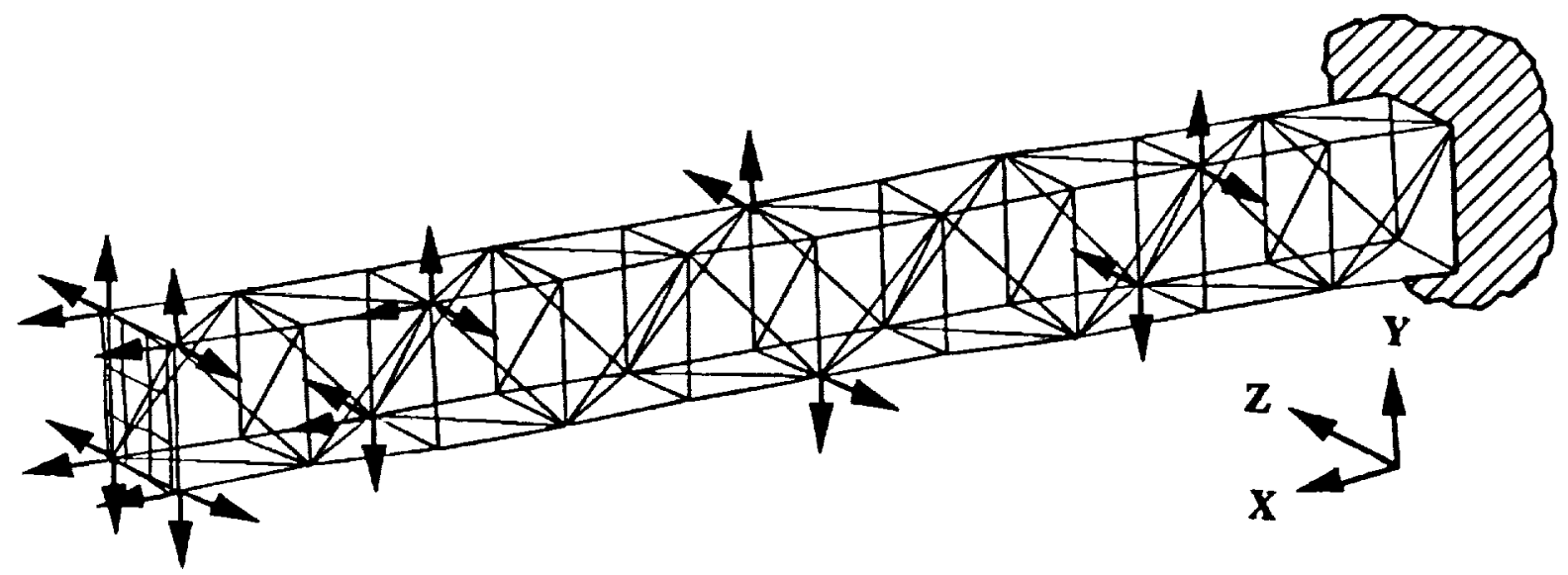

Figure 5. Set 1 retained DOF.

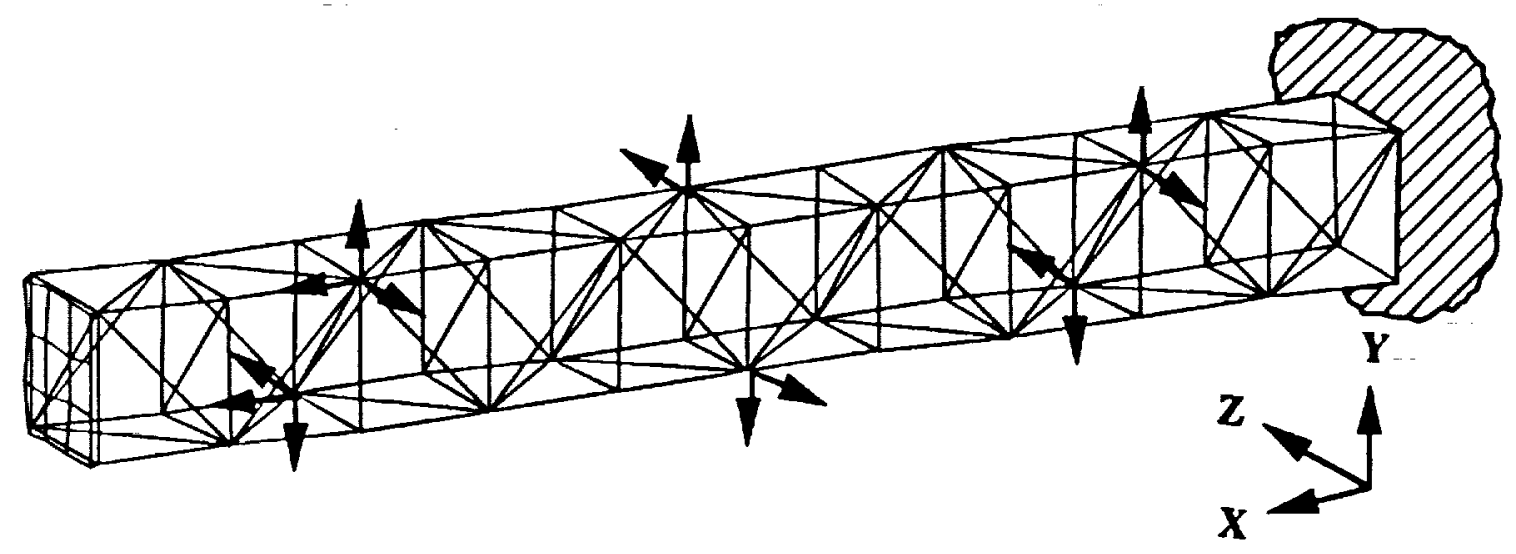

Figure 6. Set 2 retained DOF. 


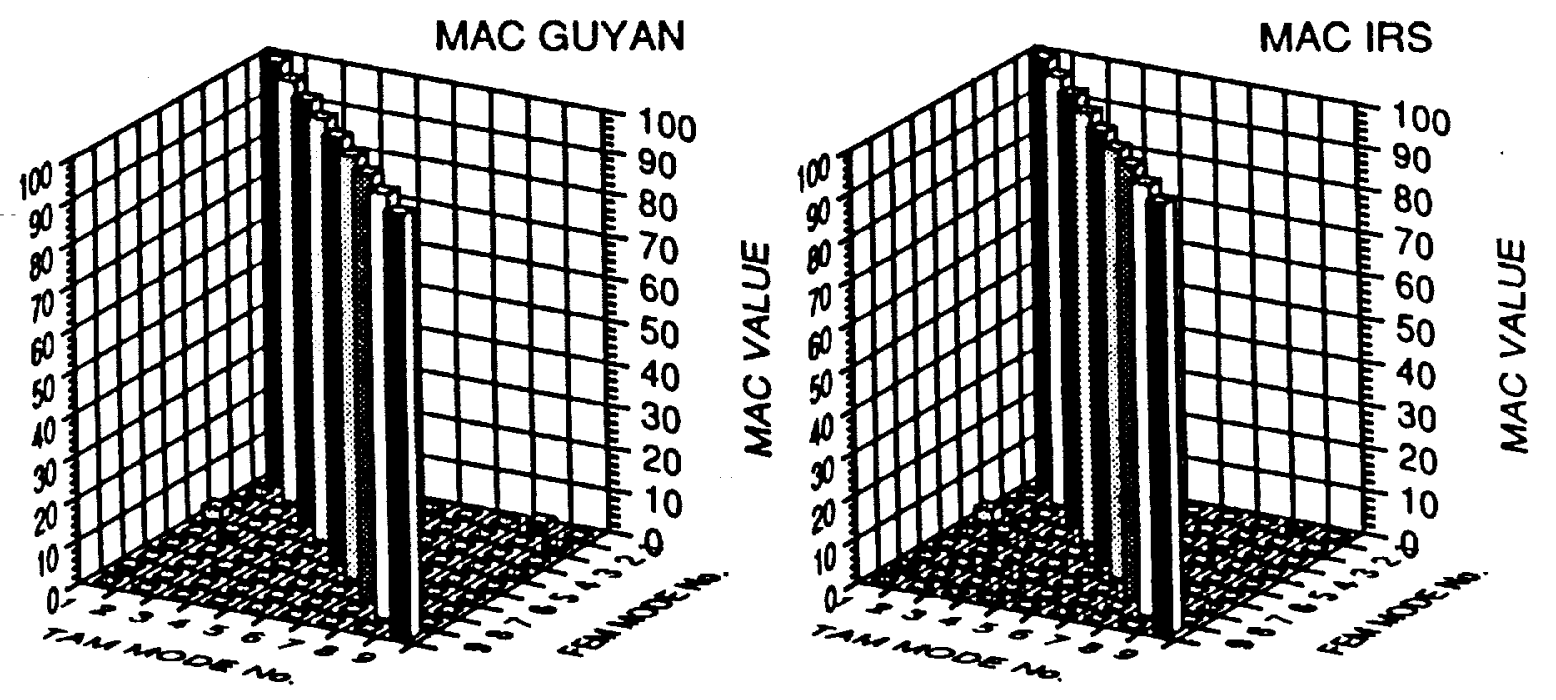

Figure 8. Modal assurance criterion (MAC) correlation for Guyan and IRS TAM vs. FEM analysis using set 1 .
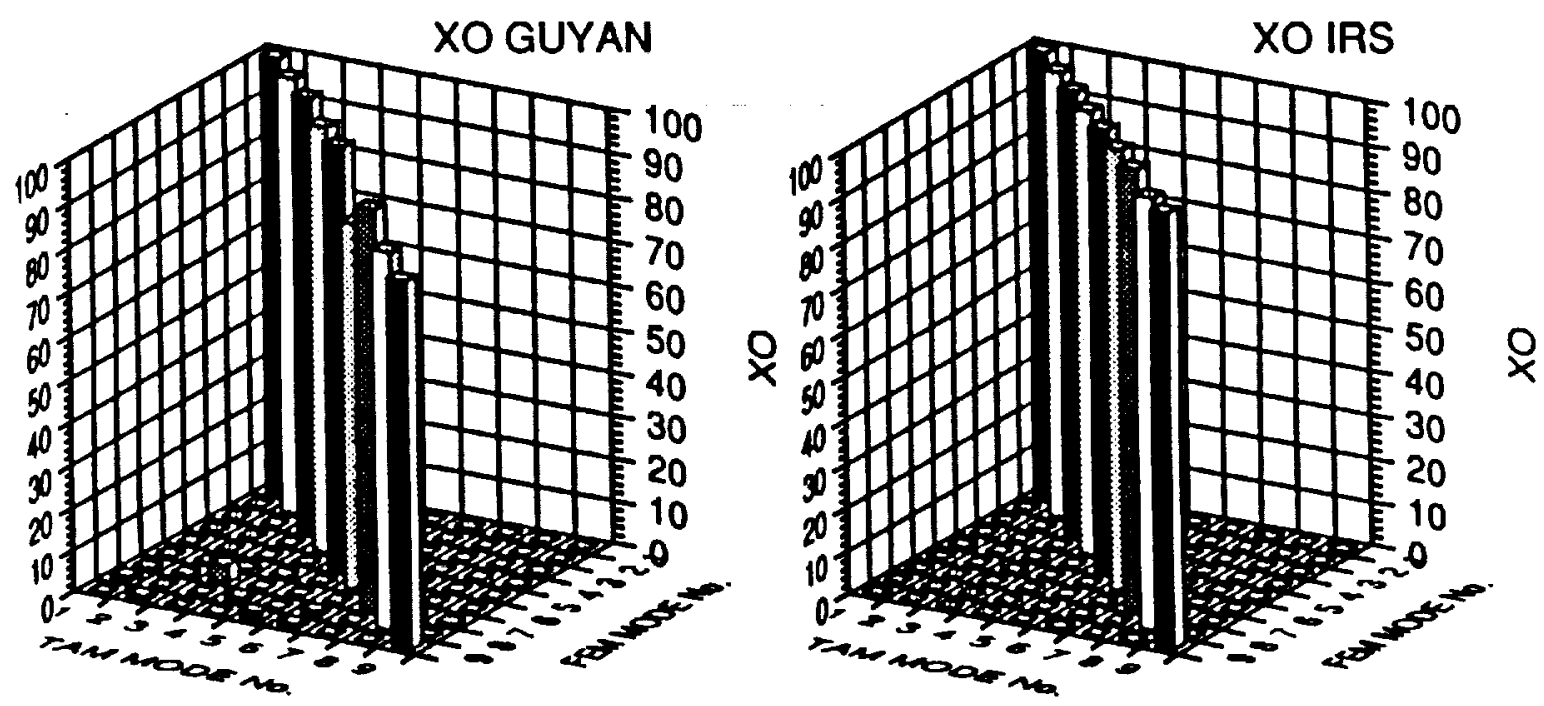

Figure 9. Cross-orthogonality criterion (XO) correlation for Guyan and IRS TAM vs. FEM analysis using set 1. 

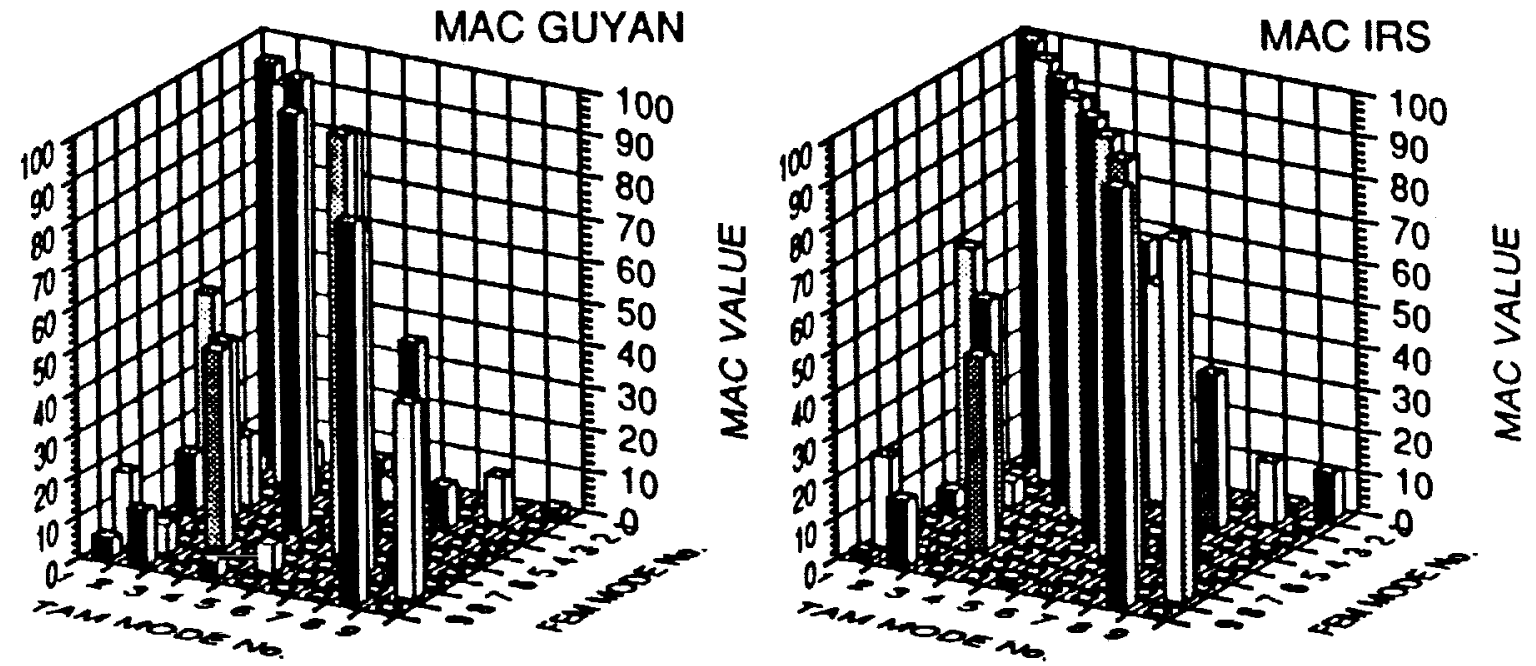

Figure 10. Modal assurance criterion (MAC) correlation for Guyan and IRS TAM vs. FEM analysis using set 2.
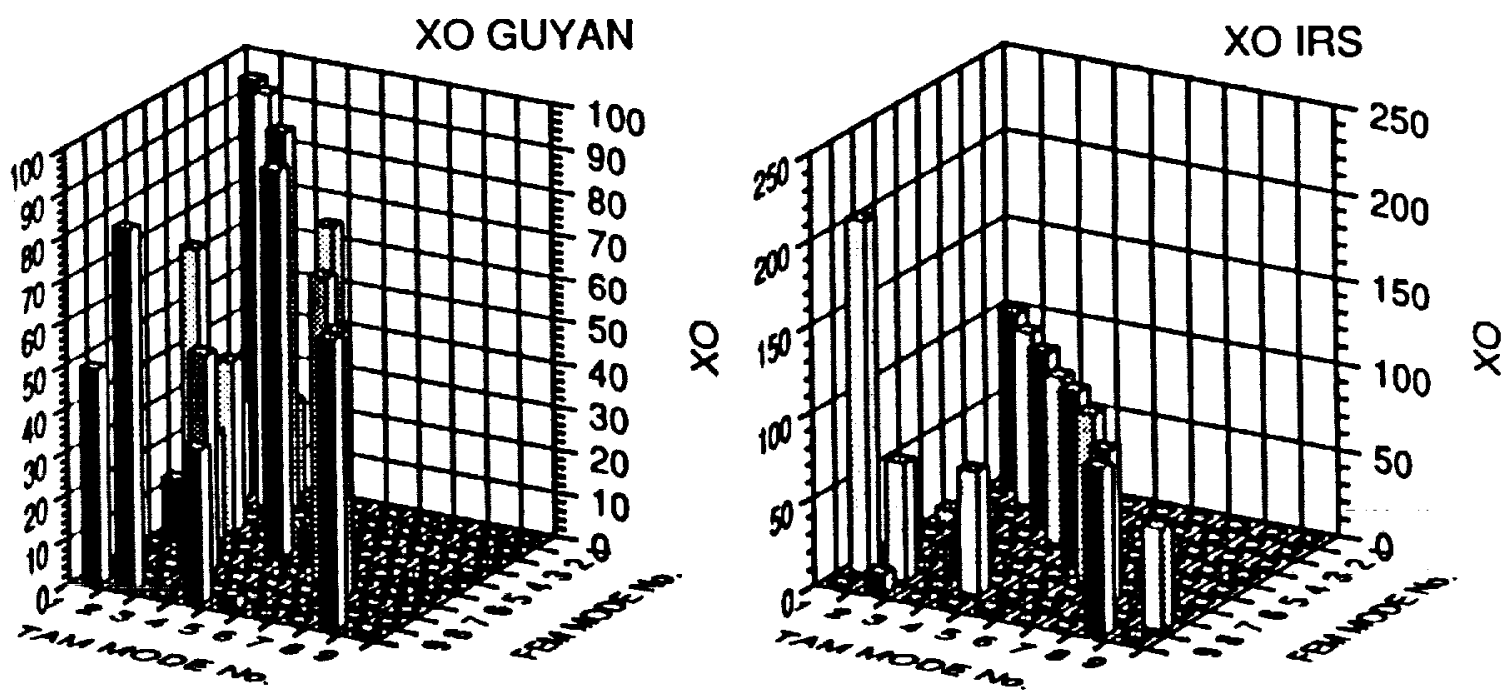

Figure 11. Cross-orthogonality criterion correlation for Guyan and IRS TAM vs. FEM Analysis using set 2. 


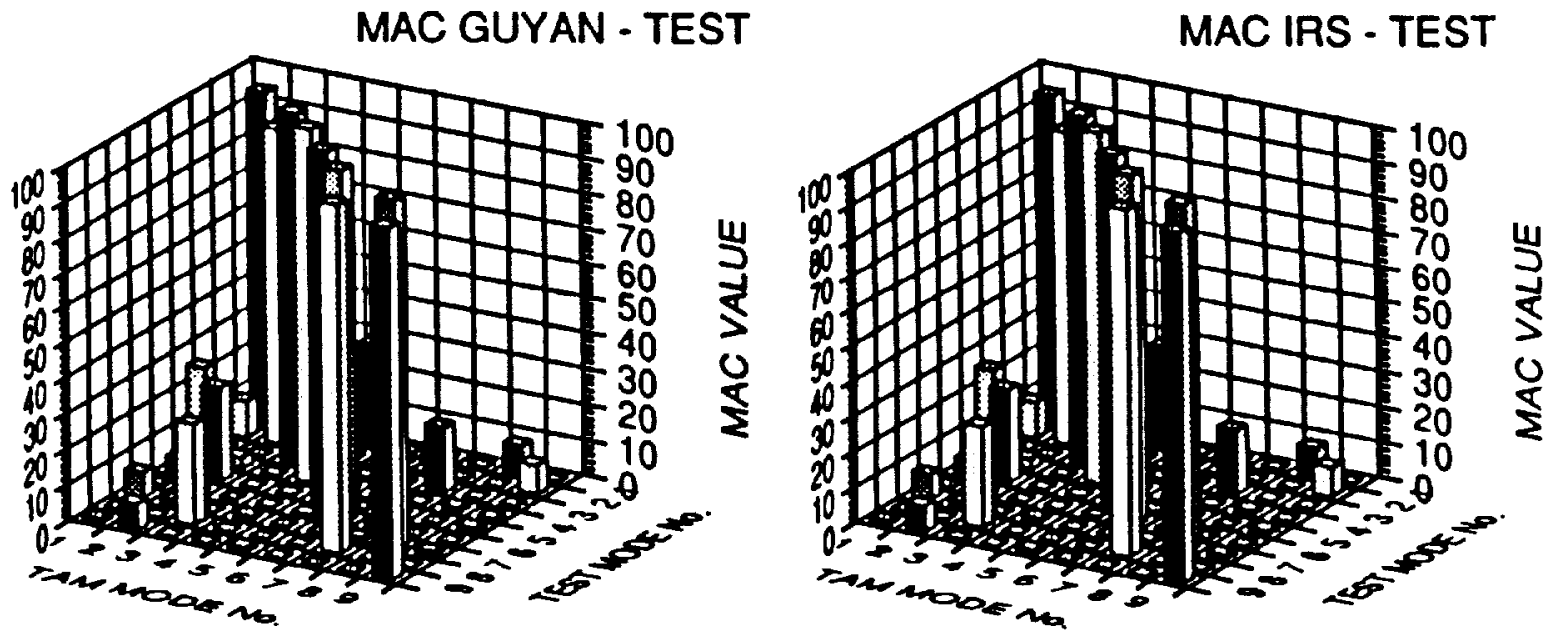

Figure 12. Modal assurance criterioN (MAC) correlation for Guyan and IRS TAM vs. Test using 98 DOF.
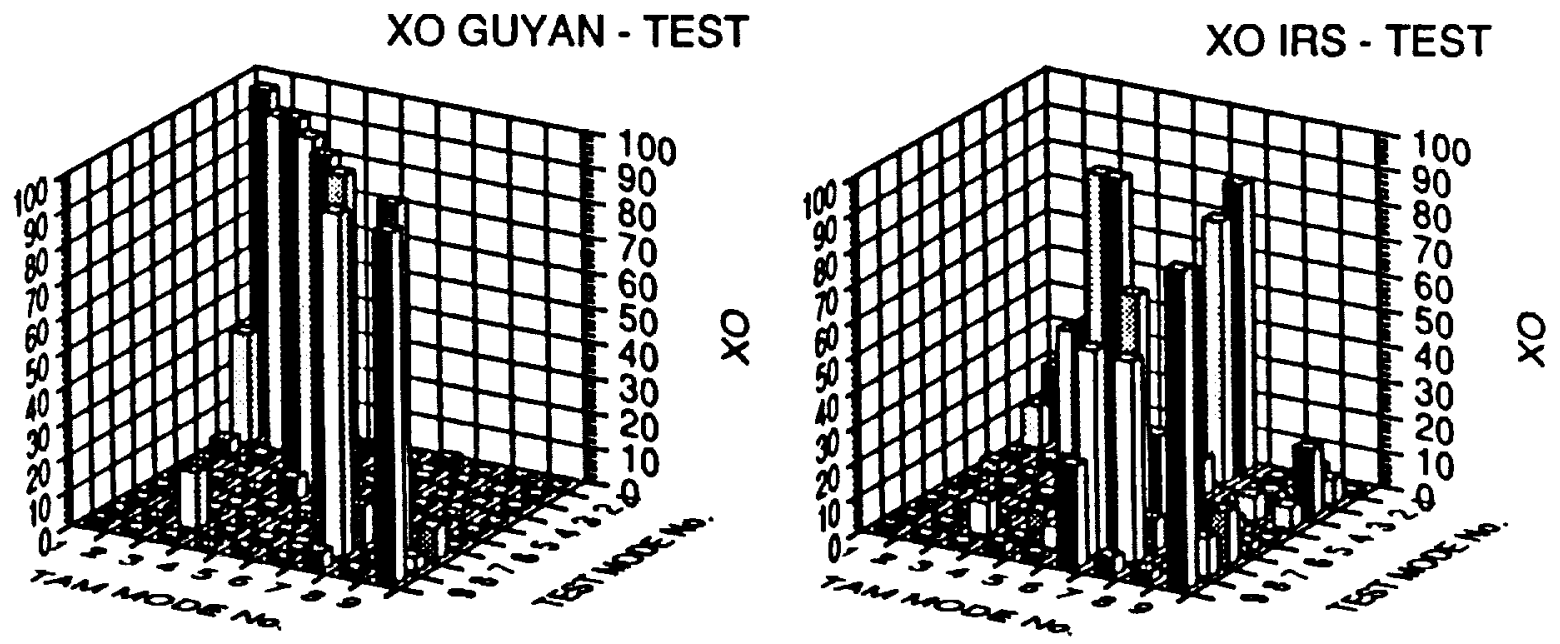

Figure 13. Cross-orthogonality criterion correlation for Guyan and IRS TAM vs. Test using 98 DOF. 


\begin{tabular}{|l|l|l} 
1. AGENCY USE ONLY (leave blank) & $\begin{array}{c}\text { 2. REPORT DATE } \\
\text { September } 1992\end{array}$ & $\begin{array}{c}\text { 3. REPORT TYPE ANO DATES COVEREO } \\
\text { Technical Memorandum }\end{array}$
\end{tabular}

\section{TITLE AND SUBTITLE}

Dynamic Test/Analysis Correlation Using Reduced

Analytical Models
5. FUNDING NUMBERS

WU 590-14-21-01

\section{AUTHOR(S)}

Paul E. McGowan, A. Filippo Angelucci, and Mehzad Javeed*

\section{PEAFORMING ORGAMIZATION NAME(S) AND ADDRESS(ES)}

NASA Langley Research Center

Hampton, VA 23681-0001

8. PERFORMING ORGANIZATION REPORT NUMBER
9. SPONSORING/MONITORING AGENCY NAME(S) AND ADDRESS(ES)

National Aeronautics and Space Administration

Washington, DC 20546-0001
10. SPONSORING/MONITORING

AGENCY REPORT NUMBER

NASA TM-107671

\section{SUPPLEMENTARY NOTES}

*Lockheed Engineering and Sciences Company. Paper presented at the 33rd Structures, Structural Dynamics, and Materials çōnference, Dallas, Texas April 13-17, 1992 .

\section{DSTRIBUTION /AVALLABILITY STATEMENT}

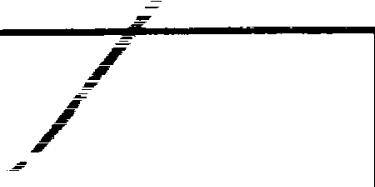

12b. DISTRIBUTION CODE

Unclassified - Unlimited

Subject Category 39

\section{ABstraCt (Maximum 200 words)}

Test/analysis correlation is an important aspect of the verification of analysis models which are used to predict on-orbit response characteristics of large space structures. This paper presents results of a study using reduced analysis models for performing dynamic test/analysis correlation. The reduced test/analysis model (TAM) has the same number and orientation of degrees-of-freedom (DOF) as the test measurements. Two reduction methods, static (Guyan) reduction and the Improved Reduced System (IRS) reduction, are applied to the test/analysis correlation of a laboratory truss structure. Simulated test results and modal test data are used to examine the performance of each method. It is shown that selection of DoF to be retained in the TAM is critical when large structural masses are involved. In addition, the use of modal test results may provide difficulties in TAM accuracy even if a large number of DOF are retained in the TAM.

\begin{tabular}{|c|c|c|c|}
\hline $\begin{array}{l}\text { 14. SUBJECT TERMS } \\
\text { Test analysis model; }\end{array}$ & reduced model; test/a & lysis correlation & $\begin{array}{l}\text { 15. NUMEER OF PAGES } \\
12\end{array}$ \\
\hline $\begin{array}{l}\text { 17. SECURITY CLASSIFICATION } \\
\text { OF REPORT } \\
\text { Unclassified }\end{array}$ & $\begin{array}{l}\text { 18. SECURITY CLASSIFICATION } \\
\text { OF THIS PAGE } \\
\text { Unclassified }\end{array}$ & $\begin{array}{l}\text { 19. SECURITY CLASSIFICATION } \\
\text { OF ABSTRACT } \\
\text { Unclassified }\end{array}$ & 20. LIMITATION OF ABSTRACT \\
\hline
\end{tabular}

